Leber's teaching as to the nature of the renewal process was weak at one point no doubt-it paid no heed to the absorbent power of the blood; but as to the source, the path, and the exit of the fluid it stands, I think, unshaken and invaluable.

\title{
REFERENCES
}

1. Leber und Pilzecker.-Neue Untersuchungen, etc. New researches on the fluid interchange in the eye. Arch.f. Ophthal.. Bd. LXIV, 1906.

2. Starling.-Jl. of Physiol., Vol. XIX, 1896.

3. Weiss, O.-Die Ernährung, etc. The nutrition and circulation of the eye. Nagel's Handbuch der Physiol., 1904.

4. Hertel. - The dependence of the intraocular pressure on the composition of the Blood. Arch.f. Ophthal., Bd. LXXXVIII, H. 2, S. 197, 1914.

5. Seidel.-Arch.f. Ophthal., Bd. CI, S. 403 (foot-note), 1919.

6. Lehmann and Meesmann.-Pflüger's Arch. f. Physiol., Bd. CCV, S. 210, 1924.

7. Duke-Elder. - Intraocular and osmotic pressure. Ocular circulation. Brit. Jl. of Ophthal., Vol. X, pp. 1 and 513, 1926.

8. Weiss, O.-Herkunft, und Schicksal, etc. Source and destination of the intraocular fluids. Deutsch. med. Wochenschr., SS. 21 and 63, Jan., 1925.

9. Duke-Elder. - The nature of the intraocular fluids. Monograph Supplement to Brit. Jl. of Ophthal., 1927.

10 Seidel.-Experimentelle Untersuchungen, etc. Experiments on the source and movement of the intraocular fluid. A series of articles in Arch. $f$. Ophthal., 1918-1921.

11. Idem-Bd. CIV, H. 3, S. 357.

12. Nuel and Benoit.-Arch. d'Ophtal., T. XX, 1899.

13. Parsons.-Pathology of the Eye, p. 992.

14. Gifford.-The direction of the lymph-streams in the eye. Arch. of Ophthal., p. 153, 1886, and Ophthal. Rev., p. 270, 1886.

15. Ulbrich.-Rep. of Ophthal. Soc. Heidelberg., Meeting of 1907, p. 105.

16 Priestley Smith.-Glaucoma, its causes, etc. London : Churchill, 1879. Cases of dislocation of lens into anterior chamber, p. 183 and pp. 262-5.

17. Minor, J. J. - New York Med. Jl., p. 194, 1881.

18. Magitot.-Ann. d'Ocul., Vol. CLIV, 1917.

\section{VISUAL FIELD CHANGES IN PREGNANCY}

BY

\author{
H. M. TRAQUAIR \\ EDINBURGH
}

THOSE who have been sceptical as to the production of bitemporal hemianopia by pressure on the chiasma by the physiologically enlarged pituitary body in pregnancy will welcome Dr. Abramowicz's paper in the January issue of the BrITISH Journal of Ophthalmology. In 81 pregnant women Dr. Abramowicz found only five who showed "slight temporal contractions of the visual fields" and this feature he cautiously-and wisely-considers "may be occasioned by the hypertrophy of the pituitary body" 
(italics, the present writer's). Is it not possible that a closer scrutiny and a fuller consideration might dispose of even these five cases?

Recent interest in the question of bitemporal hemianopia in pregnancy dates from the Washington Congress in 1922, when Finlay(1) published his results, which were supported by those of Maud Carvill.(2) These observers found respectively that 71 per cent. and 89 per cent. of pregnant women showed bitemporal contraction of the fields in the ninth month. At the Washington meeting, de Lapersonne remarked: "Dans les champs visuels qui sont preséntés tous n'ont pas les dispositions caractéristiques de 1'hémianopsie bitemporale." This remark, which goes to the root of the matter, was allowed to pass without comment.

One may without hesitation go further than this and say that no fields from cases of uncomplicated pregnancy have yet been published which show the characteristic features of bitemporal hemianopia, even in its earliest stages.

Abramowicz states that the subject of his investigation was "the contraction of the outer limits of the visual field" and refers to "slight contraction upwards and outwards" as an early symptom of chiasmal lesion. Other writers upon the fields in pregnancy have worked mainly upon the same lines and, without first laying down as an essential premise a clear definition as to what constitutes the perimetric evidence of hypophysial pressure upon the chiasma, have not hesitated to formulate positive conclusions on the basis of field changes which differ in important particulars from those present in cases of known pituitary enlargement.

What then are the characteristic features of early bitemporal hemianopia from this cause?

Cushing, than whom no better authority could have been selected, is quoted, but Cushing's words ${ }^{(3)}$ are "Stage 1 shows merely an upper temporal quadrantal defect in the colour field often with a slight slanting off of the form fields in the same quadrant." That is to say, the essential early change is not detected at the periphery of the field, but well inside the periphery, though an early peripheral change may also be demonstrable. Walker, who was responsible for the perimetry in Cushing's clinic, observes that "colour defects are practically always represented by form defects, if the visual angle is made small enough."'(4) He also states definitely that "For the detection of early pressure effects on the optic tract examination of the fields for the smallest visual angles gives the most reliable results."(5) These findings agree with my own observations ${ }^{(6)}$ and show that in early bitemporal hemianopia from upward pressure against the chiasma visual acuity over the greater part of the upper outer 
quadrant is depressed, and that this impairment is demonstrable by perimetry first in the interior of the quadrant and later, when more advanced, at the periphery in addition.

Abramowicz did not test the interior of the field with small visual angles, basing his opposition to this method on the statements of Hess, ${ }^{(7)}$ to which Köllner ${ }^{(8)}$ refers. Hess's objections are purely theoretical and, presuming that the perimetrist possesses an average amount of common sense, have no weight in practice, while Köllner (9) himself praises Bjerrum's screen which he states is, "in association with the perimeter, a valuable and indispensable means for the detection of fine, or commencing field defects." While, partly at any rate, adopting Cushing's evidence as to the early signs of bitemporal hemianopia, Dr. Abramowicz apparently mistrusts the method of perimetry used in Cushing's clinic, although this, the quantitative method of Roenne and Bjerrum, has yielded invaluable and unquestioned additions to our knowledge of the field defects due to enlargement of the hypophysis.

In none of the five cases reported is an "upper outer quadrantal defect of the colour field" mentioned either with or without a corresponding "slight slanting off of the form field in the same quadrant." In number 23, the contraction of the colour field (green) was concentric; in number 58 , there was bilateral "outupward" contraction of the field for white but the state of the colour fields is not mentioned; in the other three, there was "temporal contraction" for red and green ; in number 53 , for green only on both sides; in number 54 , for both colours on the left side only; in number 14 , for both colours, whether uni- or bilateral is not mentioned.

Now, field changes which can be demonstrated by so large a visual angle as $5 / 300\left(57^{\prime}\right)$, the angle used in these investigations, are relatively gross, i.e., they indicate a severe depression of visual acuity in the area affected. Defects of this intensity, limited to the periphery of the field, and unassociated with a quadrantal defect of the colour field or associated only with concentric contraction for colour, have not hitherto been observed in the initial stages of bitemporal hemianopia. Moreover, "temporal contraction" for colour, if by this is meant a contraction along the horizontal meridian, affecting approximately equally both upper and lower temporal quadrants, is a very unreliable indication of organic. lesion, more especially if green is the colour used, unless strongly supported by confirming tests, and in any case has never been shown to be an early sign of pressure on the chiasma.

If bitemporal hemianopia due to pregnancy exists, the field changes might naturally be expected to correspond to the earliest changes demonstrable in cases of pituitary tumour, i.e., normal 
periphery with a quadrantal change easily demonstrable by coloured or small white objects in the region $10^{\circ}$ to $40^{\circ}$ from the fixation point.

The absence of scotoma is another feature which requires explanation. In typical bitemporal hemianopia due to pituitary tumour a scotoma is always present in the central part of the upper 'outer quadrant, unless the hypophysial enlargement has been very slow as in the usual type of chronic acromegaly. If the pituitary body in normal pregnancy really enlarges to the extent required actually to press upon the chiasma, the growth must be fairly rapid, and one would expect to find, not only the scotomatous type of hemianopia, but also headache from the irritation of the nerves of the diaphragma sellae.

It seems, therefore, very doubtful, to say the least, whether the five cases in question present any features indicative of bitemporal hemianopia from pituitary pressure, and, having regard to the cautious way in which his conclusions are expressed, it is possible that this view may not be altogether surprising or unwelcome to Dr. Abramowicz himself.

If the study of the characters of these field changes gives negative results as regards the hypophysial pressure hypothesis, it affords ample positive evidence of their psychical origin, which is the alternative explanation. Psychical or functional field changes, manifested by perimetric examination, have their own distinctive characters, and the charts published by Finlay and Carvill, for example, suggest this origin very strongly. No special tests, essential in the circumstances, to exclude functional changes are mentioned in their reports.

The contraction is temporal rather than supero-temporal, affecting the lower as well as the upper quadrants. While the nasal fields were often contracted also, the colour fields were sometimes concentrically restricted. Carvill found the edge of the field quite sharp, as is so characteristic of psychical defects and so unusual in pressure bitemporal hemianopia, but does not state how this feature should be interpreted.

Temporal restriction of the field is quite a common form of psychical defect, it is a milder form of the same impairment which, when more fully developed, appears as an approximately circular concentric contraction. As the gradient of perception in the field, from maximum at the visual axis to zero at the periphery, is more sloping on the temporal than on the nasal side, the defect is likely to be more easily demonstrated by perimetry on the temporal side.

That these field changes are of psychical origin was pointed out by Bellinzona and Tridontani and no evidence has hitherto been produced which impairs the validity of their view. 


\section{REFERENCES}

1. Finlay.-Intern. Cong. Ophthal., Washington, D.C., U.S.A., p. 144, 1922.

2. Carvill.-Ibid, and also Amer. Jl. Ophthal., Series 3, Vol. VI, p. 885, 1923.

3. Cushing and Walker.-Brain, Vol. XXXVII, p. 349, 1915.

4. Walker. -Arch. of Ophthal., Vol. XLVI, p. 540, 1917.

5. Idem.- "Colour interlacing and perimetry,"-Trans. Amer. Ophthal. Soc., 1916.

6. Traquair.-Edin. Med. Jl., Sept., 1913 ; Ophthal. Rev. p. 72, 1914 ; Brit. Jl. of Ophthal., April-June, 1917.

7. Hess. -A rch. f. Augenheilk., Bd. LXXXIV, S. 1, 1919 ; Ibid, Bd. LXXXV, S. $1,1920$.

8. Köllner.- "Die Untersuchungsmethoden." Graefe Saemisch, Bd: III 3 Aufl., 1925.

9. Idem. - Loc. cit.

\section{OBSERVATIONS ON THE \\ COMPLICATIONS FOLLOWING 4,000 CASES OF CATARACT EXTRACTION}

BY

\section{M. Cruickshank, Major, I.M.S.}

THESE cases represent a part of the work done by Dr. Holland of Quetta, and his staff, during the 1923, 1924, and 1926 seasons at Shikarpur, Sind. The season commences on the first of January and closes at the end of the third week in February. During these three seasons 4,027 cases of cataract were dealt with, 1,322, 1,455, and 1,250 in the respective seasons. While a more or less equal share of the operative work falls to each surgeon, the work of the out-patient department is largely controlled by Dr. Holland, because of his intimate knowledge of the various languages spoken. To me fell the care of the patients in the wards, and I was afforded the unique opportunity of closely examining all the eye cases, noting complications and registering visual results. A system, simple yet effective, was devised whereby everything pertaining to a cataract case could be noted. Each patient on entering the operating theatre had his name written in the cataract book and numbered. Particulars were noted with regard to tension, operative procedure followed, and any complications occurring during the operation. These points, noted in the cataract book were later transcribed to small notebooks used in the wards, the patient's serial number in the cataract book being the number of the page in the small books, containing all the facts relating to the case. It was team work, each member of the team doing his best to make the records as complete and accurate as possible by seeing that the slightest complication, occurring during the operation, however trivial it might appear to himself, was entered against the patient's number and name in the cataract book.

With regard to the selection of patients and the choice of 